\title{
Effects of six weeks high-intensity interval training and resistance training in adults with obesity and sleep related breathing disorders
}

\author{
Khomkrip Longlalerng ${ }^{1 *}$ \\ Anucha Nakeaw ${ }^{1}$ \\ Asmu-e Charawae ${ }^{1}$ \\ Powpachara Reantong ${ }^{1}$ \\ Usamawee Prangyim ${ }^{1}$ \\ Nutjaree Jeenduang ${ }^{2}$
}

${ }^{1}$ Walailak University, School of Allied Health Science, Department of Physical Therapy - Thasala - Nakhon Si Thammarat - Thailand.

${ }^{2}$ Walailak University, School of Allied Health Science, Department of Medical Technology - Thasala - Nakhon Si

Thammarat - Thailand.

\author{
*Corresponding author: \\ Khomkrip Longlalerng \\ E-mail: klugklig016@gmail.com / \\ khomkrip.lo@wu.ac.th
}

Received: August 24, 2020;

Accepted: November 23, 2020.

\begin{abstract}
Introduction: The effects of high-intensity interval training (HIIT) combined with resistance training (RT) in adults with obesity and sleep-related breathing disorders (SRBDs) is limited. Objective: This study aimed to examine the effects of HIIT combined with RT on subjective sleep disorders in adults with obesity and SRBDs. Material and Methods: This study was a pre- and post-test design. Seventeen adults with obesity and SRBDs were recruited into the study. They received 24 minutes of HIIT and 30 minutes of RT, 3 times/week for 6 weeks. The Epworth sleepiness scale (daytime sleepiness), Berlin questionnaire (snoring and daytime sleepiness category), estimated maximum oxygen consumption $\left(\mathrm{VO}_{2} \mathrm{max}\right)$, muscle strength using 1-repetition maximum, anthropometric variables, and blood biomarkers were examined at baseline and after 6 weeks of training. Results: The Epworth sleepiness scale, Berlin questionnaire (daytime sleepiness category), and the number of risks associated with sleep apnea using the Berlin questionnaire were significantly decreased after 6 weeks of training (all $\mathrm{p}<0.01)$. The estimated $\mathrm{VO}_{2}$ max and muscle strength were significantly increased at Week 6 (all $p<0.05$ ). Body weight, body mass index, \% body fat, and hip circumference were significantly decreased at Week 6 (all $p<0.05$ ). No significant changes were observed in blood biomarkers, except for fasting blood glucose $(\mathrm{p}<0.01)$. Conclusion: Six weeks of HIIT combined with RT has beneficial effects on subjective sleep disorders, estimated $\mathrm{VO}_{2}$ max, muscle strength, and most anthropometric variables in adults with obesity and SRBDs.
\end{abstract}

Keywords: High-intensity Interval Training; Resistance Training; Sleep-related Breathing Disorders; Obesity. 


\section{INTRODUCTION}

Sleep-related breathing disorders (SRBDs) are a wide spectrum of breathing difficulties during sleep in adults ${ }^{1}$. Its clinical characteristics range from habitual snoring, fragmented sleep to intermittent hypoxia, and obstructive sleep apnea $(\mathrm{OSA})^{1-3}$. The most severe form of SRBDs is OSA, which ranges from 3.7-93.3\% prevalence in Asian adults depending on age, gender, body composition, and comorbidities ${ }^{4}$. SRBDs are related to functional decline, excessive daytime sleepiness (EDS), cognitive impairment, mood disturbance, medical comorbidities, and obesity ${ }^{3,5}$. There is evidence to support the suggestion that SRBDs are a preliminary condition of endothelial dysfunction leading to atherosclerosis and cardiovascular diseases ${ }^{6}$. Therefore, early detection and intervention of problems related to SRBDs are necessary to eliminate the event of fatal effects.

Conservative intervention has been established as an alternative treatment for SRBDs, such as behavioral modification, including exercise and/or combined with diet control ${ }^{7-13}$. It was found that these interventions were beneficial effects on sleep parameters ${ }^{7-13}$. Previously, a number of studies found that EDS $^{7,9,11}$, snoring ${ }^{10}$, and sleep indices ${ }^{9,12,13}$ were improved after exercise intervention. More recently, high-intensity interval training (HIIT) has become more attractive form of exercise program because it is capable of reducing cardiovascular risk factors related to obesity and improving physical fitness ${ }^{14,15}$. A growing body of evidence revealed that HIIT is safe and practical to apply with many vulnerable subjects ${ }^{14,15}$. It has superior effectiveness over traditional moderate-intensity aerobic training in mitigating many circumstances ${ }^{15}$. In addition, resistance training (RT) is considered as adjuvant therapy for weight management in obese adults ${ }^{16}$. There was a study showing that RT could provide a greater advantage if combined with aerobic exercise for obese adults ${ }^{17}$.

Nevertheless, there are limited studies examining the combined effects of aerobic exercise in terms of a HIIT program with RT for adults with obesity and SRBDs. Thus, this study aimed to examines the effects of HIIT and RT on the subjective sleep disorders of adults with obesity and SRBDs. We hypothesized that six weeks of this combined intervention would significantly improve the subjective sleep disorders of adults with obesity and SRBDs.

\section{MATERIAL AND METHODS}

\section{Study population}

Male and female adults aged 20-53 years were recruited into the study. They were asked to complete two sleep questionnaire forms, including the Epworth sleepiness scale and Berlin questionnaire for first time screening. The study was conducted at Thasala District, Nakhon Si Thammarat Province, Thailand, from February to April 2020. The inclusion criteria for participants consisted of: 1) those who were suspected to have SRBDs from the questionnaire forms (the Epworth sleepiness scale $\geq 10$ or snoring item of the Berlin questionnaire $\geq 2$ ); and 2) those who were classified as a person with obesity based on their BMI using the criteria of the International Obesity Task Force World Health Organization Western Pacific Region $\left(\mathrm{BMI} \geq 25 \mathrm{~kg} / \mathrm{m}^{2}\right)^{18}$. The exclusion criteria for participants consisted of: 1) those who have received other treatments related to SRBDs or have undergone behavioral modification programs; and 2) those who have underlying diseases (e.g., cardiorespiratory disorder, hypertension, diabetes mellitus, neurological disorders, or any orthopedic problems that limited exercise performance). This study was approved by the Human Research Ethics Committee of Walailak University, Nakhon Si Thammarat Province (\#WUEC-20-006-01). Written informed consent was acquired from all participants (Thai Clinical Trials Registry: TCTR20200216001).

\section{Study design}

This study was a time-series design with pre- and posttest comparisons. Participants were instructed to perform a 6-week HIIT combined with RT $(\mathrm{n}=21)$. They were not allowed to participate in other exercise programs during the study period. Participants were suggested to control their diet by the researchers. The primary outcome measurement were daytime sleepiness using the Epworth sleepiness scale, and OSA risk using the Berlin questionnaire, which is composed of the snoring category (items 1-5), daytime sleepiness category (items 6-8), and questions about having obesity or hypertension (items 9-10). According to the interpretation procedures based on the original version, if the respondents had a total score $\geq 2$ in category 1 and 2 , have hypertension, or are identified as obese, then they are classified as having a risk of sleep apnea. If participants had a positive risk $\geq 2$ in three categories, then they are identified as having a high risk of OSA. The secondary outcomes included anthropometric variables [i.e., body mass index (BMI); percent body fat $(\% \mathrm{BF})$; neck, waist, and hip circumferences $(\mathrm{NC}, \mathrm{WC}, \mathrm{HC})$; and waist hip ratio $(\mathrm{W} / \mathrm{H})]$, the estimated maximum oxygen consumption (estimated $\mathrm{VO}_{2}$ max), muscle strength using 1 repetition maximum (1-RM) for the seven major muscles in the body, and blood biomarkers [triglyceride, total cholesterol (TC), high density lipoprotein cholesterol (HDL-C), low density lipoprotein cholesterol (LDL-C), and fasting blood glucose (FBG)]. All variables were examined at baseline and after 6 weeks of training. A flow chart of the study is shown in Figure 1.

\section{Exercise intervention program}

The exercise program comprised 24 minutes of HIIT and 30 minutes of RT. All participants were asked to participate in the exercise program at the physical therapy laboratory fitness room, Walailak University, three times weekly for six weeks. The exercise program was supervised by a physiotherapist. The HIIT program was adapted based on previous studies ${ }^{19,20}$. The HITT intensity began at 85 maximum heart rate (MHR), and MHR was calculated using the formula (220-age) prior to participants performing the $1^{\text {st }}$ exercise session. The HIIT program comprised of four 3-min bouts at high intensity 


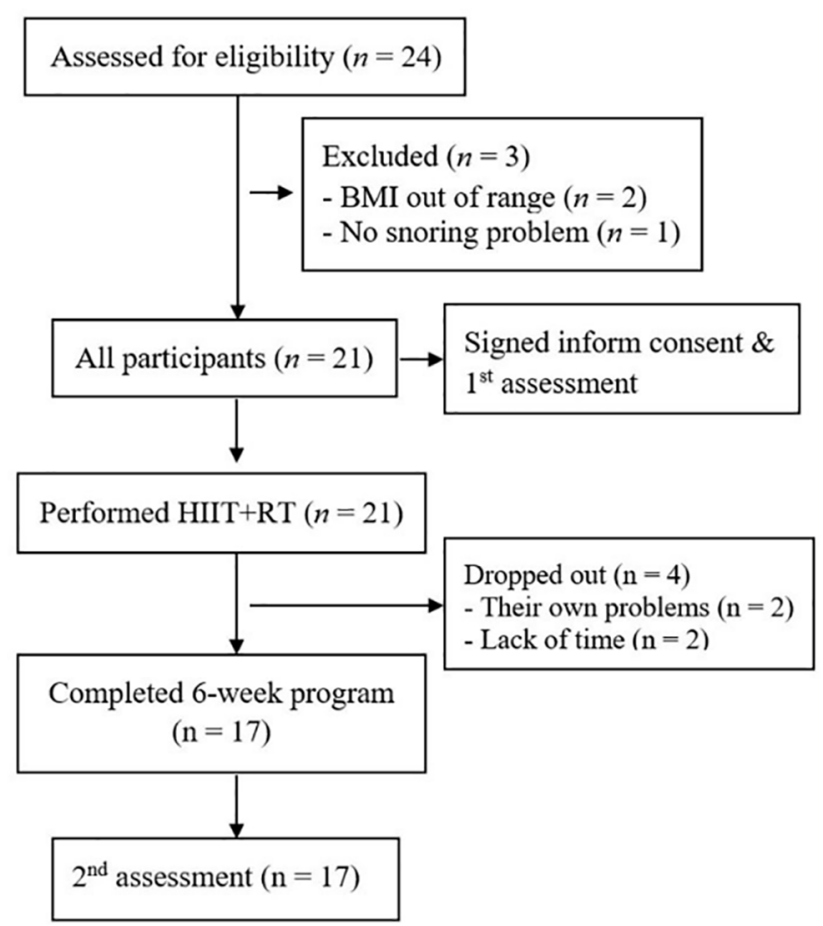

Figure 1. Flow chart of the study

( $>85 \%$ MHR), separated by 3 minutes of active recovery at moderate intensity $(60-70 \%$ MHR). The HIIT exercise types included treadmill running, outdoor running, leg ergometer cycling, and ball activities. A polar heart rate sensor (H10) was used to monitor exercise intensity for each exercise session. Afterwards, a 30-minute RT program was performed using weight machines, dumbbells, and body work ${ }^{16}$. It began with $50 \%$ of $1-\mathrm{RM}$, and gradually progressed by increasing $10 \%$ every 2 weeks. The repetitions of each pose were between $10-$ 15 times with 1-minute rest intervals, 2 sets per pose. The RT poses included the chest press machine, biceps curls, push-ups, abdominal curl-ups, lateral pulldowns, leg presses, and leg curls.

\section{Outcome measurements}

\section{Subjective sleep disorders}

The Epworth sleepiness scale (ESS) is used to assess excessive daytime sleepiness (EDS), and has been translated into a Thai version by Banhiran et al. (2011) ${ }^{21}$. It is a self-administered questionnaire which takes 2-3 minutes to complete, and it is comprised of eight circumstances for the potential of dozing off or falling asleep with a rating scale of 0 to 3 . The questionnaire shows an excellent internal consistency and test-retest reliability, and it can be properly used for assessing intervention efficacy. A total score of the ESS $>10$ is identified as a person with EDS, and there is a high risk of SRBDs. Meanwhile, the Berlin questionnaire is used to evaluate nighttime sleep issues (e.g., snoring problems), daytime sleepiness, and fatigue. It is divided into three categories including snoring, daytime sleepiness, and problems related to OSA. The Berlin questionnaire was translated into Thai by Suksakorn et al. (2014) ${ }^{22}$. It has satisfactory validity and reliability for evaluating a person with
SRBDs. It is comprised of 10 question items and takes 5 minutes to complete. The total scores of each category $\geq 2$ indicate a positive risk for having OSA. The $3^{\text {rd }}$ category is determined as a positive risk if participants have hypertension or are classified as obese. Hence, if the respondents had a positive risk $\geq 2$ in three categories of the Berlin questionnaire, then they will be categorized as at high risk of OSA.

\section{Anthropometric variables}

Body weight (BW), body mass index (BMI), body fat percentage $(\% \mathrm{BF})$, fat free mass $(\mathrm{FFM})$, and muscle mass were examined using a bioelectrical impedance analyzer (Tanita SC330 , Tokyo, Japan) after $12 \mathrm{~h}$ of overnight fasting. A tape measure was used to measure waist circumference (WC) at the umbilical level. Hip circumference (HC) was measured at the prominent part of the buttock region. Neck circumference (NC) was measured at the prominent part of the thyroid cartilage. The intra-rater reliability of $\mathrm{WC}, \mathrm{HC}$, and $\mathrm{NC}$ was examined in 10 healthy subjects. They were in an acceptable range of reliability (intraclass correlation coefficient $>0.95$, all $p<0.01$ ).

\section{Physical fitness}

An estimated $\mathrm{VO}_{2} \max$ was examined using the AstrandRyhming cycle ergometer test. Participants were instructed to cycle for 6 minutes following the American College of Sports Medicine guidelines $^{16}$. The average heart rate between the last 2 minutes was used to estimate $\mathrm{VO}_{2}$ max using a nomogram. The estimated $\mathrm{VO}_{2} \max (1 / \mathrm{min})$ was adjusted with an age factor and transformed to relative estimated $\mathrm{VO}_{2} \max (\mathrm{ml} / \mathrm{kg} / \mathrm{min})$ using the formula:

Relative estimatedVO $\max (\mathrm{ml} / \mathrm{kg} / \mathrm{min})=[$ (estimated $\left.\mathrm{VO}_{2}(1 / \mathrm{min}) \times 1,000\right) /$ body weight $\left.(\mathrm{kg})\right]$

Muscle strength was measured using 1-RM for all seven large major muscle groups. It was examined using dumbbells, machine stations, and body weight. The equation for estimating 1- $\mathrm{RM}(\mathrm{kg})$ is as follows:

$1-\mathrm{RM}(\mathrm{kg})=$ lifting weight $(\mathrm{kg}) /(1-0.02 \times \text { repetitions })^{23}$

\section{Blood biomarkers}

After $12 \mathrm{~h}$ of overnight fasting, $9 \mathrm{ml}$ of blood venous samples were drawn from each participant at the antebrachial area. Total cholesterol (TC), triglyceride, high density lipoprotein cholesterol (HDL-C), and fasting blood glucose (FBG) were analyzed by the standard laboratory method. All tests were performed using an Auto Analyser A15 (BioSystems S.A, Barcelona, Spain). Low density lipoprotein cholesterol (LDL-C) was measured by the Freidewald equation.

\section{Sample size calculation}

The sample size was calculated based on a previous study $^{19}$ using G-power software (Version 3.1.9.4). AHI (7.5) and SD (11.6) were used to replace the G-power program (matched pairs) with an effect size of 0.65 , a power of 0.8 , and a significance level of 0.05 . The number of samples in this study was 17 participants. To prevent a dropout percentage, we 
added 20 percent to account for the attrition rate. Finally, 21 participants were obtained and recruited into the study.

\section{Statistical analysis}

The Shapiro-Wilk test was used to identify data distribution. The Paired sample t-test or the Wilcoxon signed rank test was chosen to compare the difference between baseline and after six weeks of training according to a distribution of data. The Spearman correlation coefficient was used to determine the correlation between data change of the sleep quality and study's variable which found significant difference between the baseline and after six weeks of training. The effect size calculation and interpretation were the following as previously guidelines ${ }^{24}$. Descriptive data was shown as mean \pm SD for continuous normal data distribution, median [Interquartile Range (IQR)] for continuous skewed data, and counts (percentages) if indicating categorical data. The Statistical Package for the Social Sciences (SPSS) Version 22.0 (SPSS Co., Ltd. Bangkok, Thailand) was used to analyze the data. The significance level was set at $p<0.05$.

\section{RESULTS}

\section{Participant characteristics}

Figure 1 illustrates a flowchart for participants throughout this study. Twenty-one obese adults with SRBDs were included in the study. The baseline characteristics of the participants are shown in Table 1 . Most of them were not exercise regularly (<2 days/week, 71\%). All participants were identified as high risk of OSA according to the Berlin questionnaire. The average exercise sessions were 16.76 sessions (93\%). The average MHR was 169 beats/minute, which was approximately 91\% MHR as calculated based on the average age at 34 years old. The average rating perceived exertion was 13.49 . The percentage of exercise types including treadmill running, leg ergometer cycling, outdoor running, and ball activities was $72 \%, 16 \%, 10 \%$, and $2 \%$, respectively. At week 2 , there were three participants excluded from the study due to lack of time to participate in the

Table 1. Baseline characteristics of the participants, mean \pm SD.

\begin{tabular}{lc|c}
\hline & $\begin{array}{c}\text { All participants } \\
(\mathbf{n = 2 1 )}\end{array}$ & $\begin{array}{c}\text { Completed } \\
\text { exercise program } \\
(\mathbf{n}=\mathbf{1 7})\end{array}$ \\
\hline Age (years) & $34 \pm 11.91$ & $34 \pm 12.39$ \\
Gender, n (\%) & $13(62 \%)$ & $12(71)$ \\
Male & $8(38 \%)$ & $5(29)$ \\
Female & $10.57 \pm 2.71$ & $10.65 \pm 2.57$ \\
Subject sleep disorders & $2.29 \pm 1.55$ & $2.35 \pm 1.73$ \\
Epworth sleepiness scale (0-24) & $0.76 \pm 0.20$ & $0.94 \pm 1.03$ \\
Berlin questionnaire (items 1-5) & $119.62 \pm 10.26$ & $117.59 \pm 7.58$ \\
Berlin questionnaire (items 6-8) & $78.48 \pm 6.95$ & $78.29 \pm 6.30$ \\
SBP (mmHg) & $76.29 \pm 11.57$ & $76.29 \pm 11.57$ \\
\hline DBP (mmHg) & & \\
\hline RHR (beats/minute) & & \\
\hline
\end{tabular}

Abbreviations: $\mathrm{SBP}=$ Systolic blood pressure; $\mathrm{DBP}=$ Diastolic blood pressure; RHR $=$ Resting heart rate. exercise program. At week 5, one participant requested to leave the study for personal reasons. Finally, there were 17 participants who completed the 6-week exercise program. There were two participants who exhibited musculoskeletal problems during the exercise program. However, there were no adverse events found in participants during the entire 6 weeks of training.

\section{Outcome variables}

EDS was significantly improved after the 6 weeks of training for both the Epworth sleepiness scale $(p<0.001)$, effect size $=1.16$ (Figure 2A), and the Berlin questionnaire (items 6-8) $(p=0.01)$, effect size $=0.44$. Meanwhile, the snoring category (items 1-5) of the Berlin questionnaire showed no differences between baseline and after 6 weeks of training $(p=0.117)$ (Figure 2B). The positive risk number in all three categories of the Berlin questionnaire showed a significant decrease after 6 weeks of training $(p<0.01)$ (Figure 2C), effect size $=0.47$. Most of the anthropometric variables showed a significant decrease after 6 weeks of training compared to baseline, including BW, $\mathrm{BMI}, \% \mathrm{BF}, \mathrm{HC}$, and $\mathrm{W} / \mathrm{H}$ ratio (all $p<0.05$ ) (Table 2), effect size $=0.51-0.64$. A significant increase in the estimated $\mathrm{VO}_{2} \max$ $(p<0.01)$, (effect size $=1.08)$ was noted after 6 weeks of training (Table 2). RHR showed no significant differences between baseline and at week $6(p=0.074)$.

The strength measured using 1-RM in all seven poses were significantly higher at week 6 compared to baseline (all $p<0.05$ ) (Table 2), effect size $=0.56-1.35$. There were no significant differences for most of the blood biomarkers (all $p>0.05$ ), except for FBG which showed a significant decrease at week 6 compared to baseline $(p<0.01$ ) (Table 2), effect size $=0.51$. There was significant correlation between the data change of ESS to data change of BW, BMI, FFM, and muscle mass ( $p=0.004, p=0.005, p=0.010$, and $p=0.015$, respectively). There was a significant correlation between the change score of Berlin QN (snoring category) to the change score of muscle strength (chest press) $(p=0.008)$ (Table 3).

\section{DISCUSSION}

This study was the first to determine the effects of a short period of HIIT combined with RT on the subjective sleep problem in adults with obesity and SRBDs. The main findings revealed that 6 weeks of this combination program was able to ameliorate EDS, lower the risk of SRBDs, improve most of the anthropometric variables, and increase physical fitness in adults with obesity and SRBDs. These results are similar to previous studies which showed an improvement in sleep quality ${ }^{7,10-12,25-27}$, and sleep indices ${ }^{12,25,28}$ after completion of exercise programs. However, the study period for those studies was longer than the present study, excepted for the study of Ebrahimi et al. (2017) ${ }^{27}$ which examined the effect of yoga and aerobic exercise at week 6 and week 12. In addition, the exercise prescription of those previous studies was performed differently to our study. For example, some studies used individual aerobic exercises $(\mathrm{AE})^{7}$, AE plus $\mathrm{RT}^{12}$, diet and AE combined with $\mathrm{RT}^{10}$, home-based combination program for the aging ${ }^{11}$, and lifestyle modification 


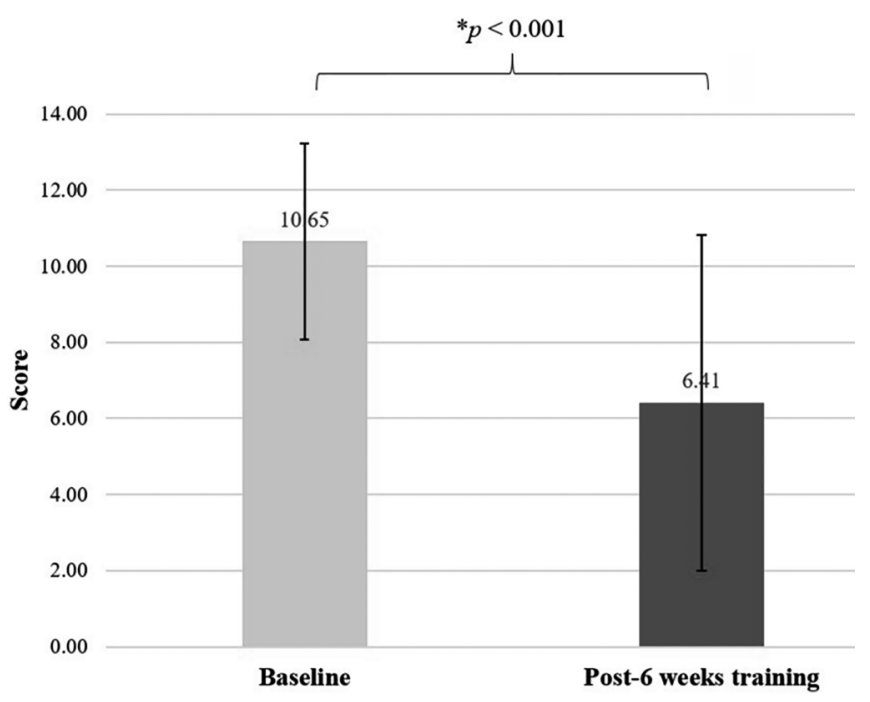

Figure 2A. Epworth Sleepiness Scale (* A statistically significant difference between baseline and post- 6 weeks of training using Paired sample t-test, $\mathrm{p}<0.001)$.

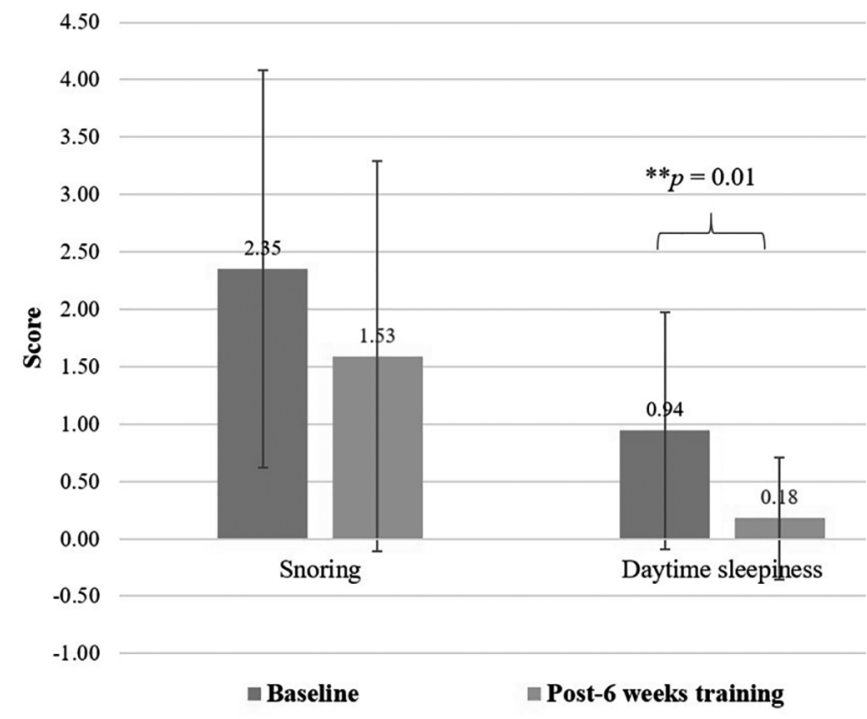

Figure 2B. Berlin Questionnaire (** A statistically significant difference between baseline and post- 6 weeks of training using Wilcoxon signed rank test, $\mathrm{p}=0.01$ ).

including diet and physical activity ${ }^{7,29}$. There were limited studies using a HIIT program for SRBDs patients ${ }^{19,20}$. There was only one study examining the effects of the HIIT program in adults with obesity, where the results showed an improvement in sleep indices and $\mathrm{EDS}^{19}$. Even though our study did not assess sleep indices using polysomnography, there was a study show the association between the sleep indices and most of the subjective sleep questionnaires ${ }^{21,22}$. Therefore, the reduction of both EDS and positive risk numbers in all three Berlin questionnaire categories may indicate an improvement in sleep indices.

The present study revealed a reduction in the anthropometric variables including $\mathrm{BW}, \% \mathrm{BF}, \mathrm{HC}$, and $\mathrm{W} / \mathrm{H}$ ratio. There is an evidence supported that these anthropometric variables are positively correlated to OSA severity ${ }^{30}$. Our results support this notation which found correlation between the change score of BW and BMI to the Epworth sleepiness scale. Therefore, $\mathrm{BW}$ and $\mathrm{BMI}$ are the cornerstone for the improvement

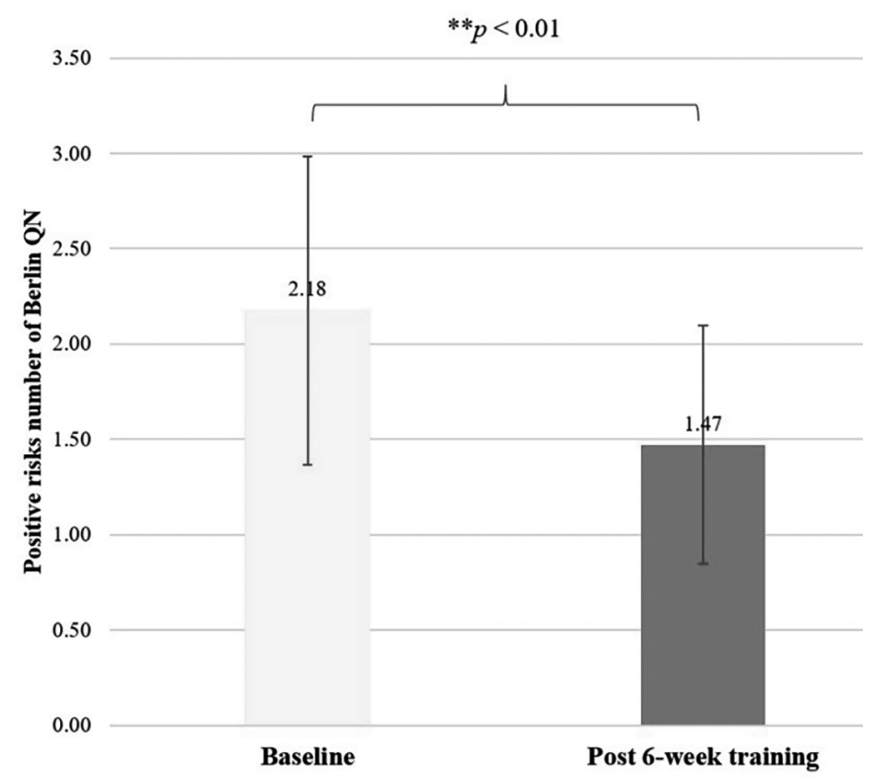

Figure 2C. Positive risk numbers of all 3 Berlin questionnaire categories (** A statistically significant difference between baseline and post- 6 weeks of training using Wilcoxon signed rank test, $\mathrm{p}<0.01$ ).

of subjective sleep disorders in our study. However, there are studies which show that OSA severity was achieved without a significant reduction in body composition, which is different to our findings $\mathrm{s}^{25,28}$. Additionally, increasing BW is also positively related to inflammatory markers and oxidative stress ${ }^{31}$. These cytokines result in airway collapse ${ }^{32}$. Hence, the effects of HIIT plus RT might cause an increase in anti-inflammatory cytokines and antioxidant agents ${ }^{33}$. Unfortunately, only blood lipid profiles and FBG were examined in the present study and no changes were found except for FBG. It might be inferred that a 6-week exercise period is insufficient to show a significant improvement in blood biomarkers. Noticeably, most of the blood biomarkers were in the normal range; thus, the ceiling for improvement was limited. In addition, the diet program of participants was not controlled in our study compared to a previous study ${ }^{10}$. This study showed an improvement in most of the blood biomarkers including insulin levels, triglyceride, and C-reactive protein after an intensive 16 weeks of AE combined with RT and a controlled diet ${ }^{10}$. Therefore, HIIT combine with RT plus dietary control might be another program challenge to prescribe for adults with obesity and SRBDs.

The estimated $\mathrm{VO}_{2}$ max and muscle strength in this study showed an apparent increase after 6 weeks of training. Our exercise program may consequently increase respiratory muscle strength, lung compliance, ventilation/perfusion matching, and vascular structure and function, which induces an improvement in intermittent hypoxemia during sleep ${ }^{34}$. Also, a reduction in the accumulation of abdominal visceral fat and adipose tissue at the chest wall might be another factor in improving breathing during sleep ${ }^{35}$. Interestingly, among of the change score of muscle strengths, there was only chest muscle was found to significantly correlate with the Berlin questionnaire (items 1-5) $(p=0.008)$. Therefore, chest muscle strength may involve in an improvement of the sleep quality such as snoring. The 
Table 2. Comparison of outcome measurements at baseline and at post- 6 weeks of training $(\mathrm{n}=17)$.

\begin{tabular}{|c|c|c|c|c|}
\hline & Baseline & Post-6 weeks & Mean difference $(95 \% \mathrm{CI})$ & $\mathrm{p}$ \\
\hline \multicolumn{5}{|l|}{ Anthropometric variables } \\
\hline $\mathrm{BW}(\mathrm{kg})$ & $83.75 \pm 15.28$ & $82.51 \pm 15.58$ & $-1.24(-2.29$ to -0.18$)$ & 0.025 \\
\hline BMI $\left(\mathrm{kg} / \mathrm{m}^{2}\right)$ & $29.42 \pm 3.52$ & $28.96 \pm 3.59$ & $-0.46(-0.83$ to -0.09$)$ & 0.018 \\
\hline$\% \mathrm{BF}^{*}$ & $29.00(26.45-36.60)$ & $28.10(25.90-35.00)$ & $-0.86(-1.32$ to -0.40$)$ & $<0.01$ \\
\hline FFM (kg) & $58.10 \pm 12.22$ & $57.92 \pm 12.33$ & $-0.18(-0.73$ to 0.37$)$ & 0.493 \\
\hline Muscle mass (kg) & $55.01 \pm 11.72$ & $54.86 \pm 11.80$ & $-0.18(-0.69$ to -0.34$)$ & 0.475 \\
\hline $\mathrm{HC}(\mathrm{cm})^{*}$ & $98.00(94.00-99.00)$ & $96.00(92.25-97.50)$ & $-3.32(-4.95$ to -1.69$)$ & $<0.001$ \\
\hline $\mathrm{W} / \mathrm{H}$ ratio & $0.85 \pm 0.06$ & $0.90 \pm 0.07$ & 0.05 (0.01 to 0.10$)$ & 0.026 \\
\hline Estimated $\mathrm{VO}_{2} \max (\mathrm{ml} / \mathrm{kg} / \mathrm{min})$ & $31.40 \pm 4.88$ & $37.77 \pm 7.63$ & 6.37 (3.35 to 9.38$)$ & $<0.001$ \\
\hline RHR (b/min) & $72.24 \pm 11.60$ & $69.76 \pm 8.77$ & $-4.47(-9.43$ to 0.49$)$ & 0.074 \\
\hline \multicolumn{5}{|l|}{ Muscle strength (1-RM, kg) } \\
\hline Chest press $(\mathrm{kg})^{*}$ & $34.00(20.50-44.50)$ & $44.00(33.00-54.50)$ & $10.59(8.17$ to 13.01$)$ & $<0.001$ \\
\hline Abdominal crunch $(\mathrm{kg})$ & $110.71 \pm 16.13$ & $132.76 \pm 23.71$ & 22.06 (13.66 to 30.45$)$ & $<0.001$ \\
\hline Leg press (kg) & $85.59 \pm 22.03$ & $99.00 \pm 23.96$ & 13.41 (5.19 to 21.63$)$ & 0.003 \\
\hline Leg curl $(\mathrm{kg})^{*}$ & $14.00(12.00-16.00)$ & $20.00(17.00-22.50)$ & $6.06(3.62$ to 8.49$)$ & 0.001 \\
\hline \multicolumn{5}{|l|}{ Blood biomarkers } \\
\hline $\mathrm{TC}(\mathrm{mg} / \mathrm{dL})$ & $236.35 \pm 43.08$ & $230.12 \pm 40.43$ & - 6.24 (to 15.14-2.67) & 0.157 \\
\hline Triglyceride (mg/dL) & $130.06 \pm 55.69$ & $135.24 \pm 57.08$ & $5.18(-23.85$ to 34.20$)$ & 0.710 \\
\hline LDL-C (mg/dL) & $154.59 \pm 43.88$ & $146.88 \pm 38.66$ & $-7.71(-19.06$ to 3.64$)$ & 0.169 \\
\hline HDL-C (mg/dL) & $58.88 \pm 12.40$ & $56.12 \pm 11.04$ & $-2.76(-5.62$ to 0.10$)$ & 0.057 \\
\hline FBG $(\mathrm{mg} / \mathrm{dL})^{*}$ & $96.00(90.50-97.00)$ & $91.00(89.50-97.50)$ & $-8.88(-14.32$ to -3.45$)$ & 0.003 \\
\hline
\end{tabular}

Abbreviations: $\mathrm{BW}=$ Body weight $; \mathrm{BMI}=$ Body mass index; $\% \mathrm{BF}=$ Percent of body fat; FFM $=$ Fat free mass; $\mathrm{NC}=$ Neck circumference; $\mathrm{WC}=$ Waist circumference; $\mathrm{HC}=$ Hip circumference; $\mathrm{W} / \mathrm{H}=$ Waist $/$ hip ratio; RHR = Resting heart rate; 1 -RM = 1-repetition maximum; $\mathrm{TC}=$ Total cholesterol; LDL-C = Low density lipoprotein cholesterol; HDL-C = High density lipoprotein cholesterol; FBG = Fasting blood glucose; *Wilcoxon signed rank test comparison [data presented as median (IQR)].

Table 3. Correlations between data change of the subjective sleep disorders to anthropometric variables, physical fitness, and FBG ( $\mathrm{n}=17$ ).

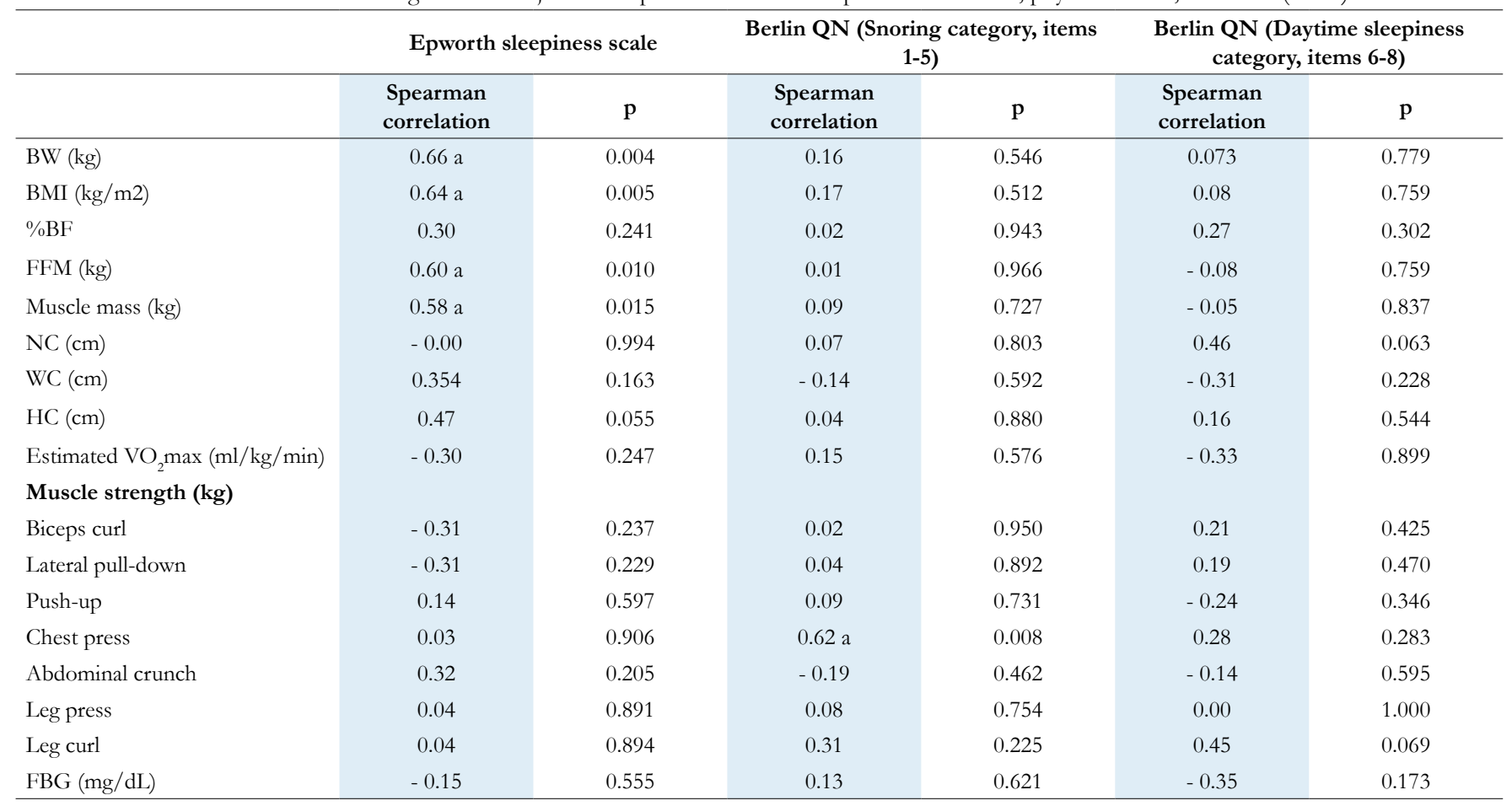

Abbreviations: $\mathrm{BW}=$ Body weight; $\mathrm{BMI}=$ Body mass index; $\% \mathrm{BF}=$ Percent of body fat; FFM = Fat free mass; $\mathrm{NC}=$ Neck circumference; $\mathrm{WC}=\mathrm{Waist}$ circumference; $\mathrm{HC}=$ Hip circumference; $\mathrm{FBG}=$ Fasting blood glucose; a Correlation is significant at $\mathrm{p}$-value $<0.05$ (two-tailed). 
findings of this study were consistent with many previous studies which showed an improvement in $\mathrm{VO}_{2} \max { }^{10,19,28}$ and muscle strength ${ }^{10}$ after completion of an exercise intervention program. However, measurement methods and exercise periods were different compared to our study. The percent of change for $\mathrm{VO}_{2}$ max in our study was greater than in a previous study ${ }^{19}$. This might be caused by the participants in our study were identified as sedentary persons with obesity who were younger than participants in the previous study ${ }^{19}$, and the severity of SRBDs in our participants was lower than the previous study ${ }^{19}$.

Even though the findings in the present study showed positive effects in most of the variables, there were some limitations observed including: 1) this study was a one group design and the next study should be a comparable study design, such as a randomized controlled usual care group; 2) the dietary of participants were not examined in this study, thus the amount of food intake should be monitored to confirm the findings; 3) inflammatory and oxidative biomarkers should be examined in a future study, and therefore the mechanism behind the improvement of sleep quality might be better explained than in the present study; and 4) the severity of SRBDs in most previous studies were moderate to severe which may be different to the present study, and therefore changes in higher degrees of SRBD severity might be easier to observe than in our study. However, the strength of this study indicated that 6 weeks of HIIT combined with RT was feasible and could improve the subjective sleep disorders in adults with obesity. These improvements are ranged in moderate to large effect size even though there were limited in sample size.

In conclusion, six weeks of HIIT combined with RT is safe and can improve subjective sleep disorders, anthropometric variables, and physical fitness. Therefore, these combined programs may be beneficial for the remedy of subjective sleep disorders in adults with obesity and SRBDs.

\section{ACKNOWLEDGEMENTS}

The authors are thankful to the officers of the Physical Therapy Laboratory, Walailak University, for the preparation of exercise equipment and testing, and management in the financial processes; and to the officers of the Medical Technology Laboratory for blood tests and analysis. Importantly, we would like to thank all of the participants who dedicated their time to join the study.

\section{REFERENCES}

1. McNicholas WT, Levy P. Sleep-related breathing disorders: definitions and measurements. Eur Respir J. 2000 Jun;15(6):988-9.

2. Tsara V, Amfilochiou A, Papagrigorakis MJ, Georgopoulos D, Liolios E. Guidelines for diagnosis and treatment of sleep-related breathing disorders in adults and children. Definition and classification of sleep related breathing disorders in adults: different types and indications for sleep studies (Part 1). Hippokratia. 2009 Jul;13(3):187-91.

3. Bananian S, Lehrman SG, Maguire GP. Cardiovascular consequences of sleep-related breathing disorders. Heart Dis. 2002 Sep/Oct;4(5):296-305.

4. Mirrakhimov AE, Sooronbaev T, Mirrakhimov EM. Prevalence of obstructive sleep apnea in Asian adults: a systematic review of the literature. BMC Pulm Med. 2013;13:10.

5. Kryger MH, Roth T, Dement WC. Principles and practice of sleep medicine. Philadelphia: Saunders; 2010.

6. Lui MM, Lam DC, Ip MSM. Significance of endothelial dysfunction in sleep-related breathing disorder. Respirology. 2013 Jan;18(1):39-46.
7. Ng SSS, Chan RSM, Woo J, Chan TO, Cheung BHK, Sea MMM, et al. A randomized controlled study to examine the effect of a lifestyle modification program in OSA. Chest. 2015 Nov;148(5):1193-203.

8. Dobrosielski DA, Papandreou C, Patil SP, Salas-Salvadó J. Diet and exercise in the management of obstructive sleep apnoea and cardiovascular disease risk. Eur Respir Rev. 2017 Jun;26(144):160110.

9. Aiello KD, Caughey WG, Nelluri B, Sharma A, Mookadam F, Mookadam M. Effect of exercise training on sleep apnea: a systematic review and meta-analysis. Respir Med. 2016 Jul;116:85-92.

10. Barnes M, Goldsworthy UR, Cary BA, Hill CJ. A diet and exercise program to improve clinical outcomes in patients with obstructive sleep apnea--a feasibility study. J Clin Sleep Med. 2009 Oct;5(5):409-15.

11. Brandão GS, Gomes GSBF, Brandão GS, Callou Sampaio AA, Donner CF, Oliveira LVF, et al. Home exercise improves the quality of sleep and daytime sleepiness of elderlies: a randomized controlled trial. Multidiscip Respir Med. 2018 Jan;13:2.

12. Bughin F, Desplan M, Mestejanot C, Picot MC, Roubille F, Jaffuel D, et al. Effects of an individualized exercise training program on severity markers of obstructive sleep apnea syndrome: a randomised controlled trial. Sleep Med. 2020 Feb;70:33-42.

13. Yang H, Liu Y, Zheng H, Liu G, Mei A. Effects of 12 weeks of regular aerobic exercises on autonomic nervous system in obstructive sleep apnea syndrome patients. Sleep Breath. 2018 Dec;22(4):1189-95.

14. Weston KS, Wisløff U, Coombes JS. High-intensity interval training in patients with lifestyle-induced cardiometabolic disease: a systematic review and meta-analysis. Br J Sports Med. 2014 Aug;48(16):1227-34.

15. Ramos JS, Dalleck LC, Tjonna AE, Beetham KS, Coombes JS. The impact of high-intensity interval training versus moderate-intensity continuous training on vascular function: a systematic review and meta-analysis. Sports Med. 2015 May;45(5):679-92.

16. American Colleage of Sports Medicine (ACSM). ACSM's guidelines for exercise testing and prescription. $9^{\text {th }}$ ed. Philadelphia: Wolters Kluwer/ Lippincott Williams \& Wilkins; 2014.

17. Villareal DT, Aguirre L, Gurney AB, Waters DL, Sinacore DR, Colombo $\mathrm{E}$, et al. Aerobic or resistance exercise, or both, in dieting obese older adults. N Engl J Med. 2017 May;376(20):1943-55.

18. World Health Organization (WHO). Regional Office for the Western Pacific. The Asia-Pacific perspective: redefining obesity and its treatment: Sydney: Health Communications Australia/WHO; 2000.

19. Karlsen T, Nes BM, Tjønna AE, Engstrøm M, Støylen A, Steinshamn S. High-intensity interval training improves obstructive sleep apnoea. BM] Open Sport Exerc Med. 2017 Feb;2(1):bmjsem-2016-000155.

20. Longlalerng K, Sonsuwan N, Uthaikhup S, Kietwatanachareon S, Kamsaiyai W, Panyasak D, et al. High-intensity interval training combined with resistance training improved apnea-hypopnea index but did not modify oxygen desaturation index and oxygen saturation nadir in obese children with obstructive sleep apnea. Sleep Breath. 2020 Jun;24(2):571-80.

21. Banhiran W, Assanasen P, Nopmaneejumruslers C, Metheetrairut C. Epworth sleepiness scale in obstructive sleep disordered breathing: the reliability and validity of the Thai version. Sleep Breath. 2011 Sep;15(3):571-7.

22. Suksakorn S, Rattanaumpawan P, Banhiran W, Cherakul N, Chotinaiwattarakul W. Reliability and validity of a Thai version of the Berlin questionnaire in patients with sleep disordered breathing. J Med Assoc Thai. 2014 Mar;97(Suppl 3):S46-S56.

23. Adams GM. Exercise physiology laboratory manual. $3^{\text {rd }}$ ed. Boston McGraw-Hill; 1998.

24. Fritz C, Morris P, Richler J. Effect size estimates: current use, calculations, and interpretation. J Exp Psychol Gen. 2012 Feb;141(1):2-18.

25. Kline CE, Crowley EP, Ewing GB, Burch JB, Blair SN, Durstine JL, et al. The effect of exercise training on obstructive sleep apnea and sleep quality: a randomized controlled trial. Sleep. 2011 Dec;34(12):1631-40.

26. Norman JE, Von Essen SG, Fuchs RH, McElligott M. Exercise training effect on obstructive sleep apnea syndrome. Sleep Res Online. 2000;3(3):121-9.

27. Ebrahimi M, Guilan-Nejad TN, Pordanjani AF. Effect of yoga and aerobics exercise on sleep quality in women with type 2 diabetes: a randomized controlled trial. Sleep Sci. 2017 Apr/Jun;10(2):68-72.

28. Sengul YS, Ozalevli S, Oztura I, Itil O, Baklan B. The effect of exercise on obstructive sleep apnea: a randomized and controlled trial. Sleep Breath. 2011 Jan;15(1):49-56.

29. Tuomilehto HPI, Seppä JM, Partinen MM, Peltonen M, Gylling H, Tuomilehto JOI, et al. Lifestyle intervention with weight reduction: firstline treatment in mild obstructive sleep apnea. Am J Respir Crit Care Med. 2009 Feb;179(4):320-7.

30. Dixon JB, Schachter LM, O’Brien PE. Predicting sleep apnea and excessive day sleepiness in the severely obese: indicators for polysomnography. Chest. 2003;123(4):1134-41.

31. Lavie L, Vishnevsky A, Lavie P. Oxidative stress and systemic inflammation in patients with sleep apnea: role of obesity. Sleep Biol Rhythms. 2007 Mar;5(2):100-10. 
32. Santos RVT, Tufik S, De Mello MT. Exercise, sleep and cytokines: is there a relation?. Sleep Med Rev. 2007 Jun;11(3):231-9.

33. Bogdanis GC, Stavrinou P, Fatouros IG, Philippou A, Chatzinikolaou A, Draganidis D, et al. Short-term high-intensity interval exercise training attenuates oxidative stress responses and improves antioxidant status in healthy humans. Food Chem Toxicol. 2013 Nov;61:171-7.
34. O'Donnell DE, McGuire M, Samis L, Webb KA. General exercise training improves ventilatory and peripheral muscle strength and endurance in chronic airflow limitation. Am J Respir Crit Care Med. 1998 May;157(5 Pt 1):1489-97.

35. Parameswaran K, Todd DC, Soth M. Altered respiratory physiology in obesity. Can Respir J. 2006 May/Jun;13(4):203-10. 